\title{
XIV. The charges on thermions produced in air and hydrogen at atmospheric pressure
}

\section{J.C. Pomeroy M.A.}

To cite this article: J.C. Pomeroy M.A. (1912) XIV. The charges on thermions produced in air and hydrogen at atmospheric pressure , Philosophical Magazine Series 6, 23:133, 173-182, DOI: 10.1080/14786440108637210

To link to this article: http://dx.doi.org/10.1080/14786440108637210

曲 Published online: 20 Apr 2009.

Submit your article to this journal $₫$

Џll Article views: 2

Q View related articles $₫$ 
to be a very sensitive indicator of thermal equilibrium. It is questionable, indeed, whether it ever has been observed hitherto. Finally, as regards conclusion (3), it seems to be corroborated by Young's remark (p. 814) about a wider limit of opalescence for positive than for negative deviations from the critical temperature.

It may be noted that a similar theory refers to the analogous phenomena near the critical point of separation of binary mixtures*. The opalescence of the two coexisting liquid phases below this point does not seem to have been observed hitherto, no doubt only owing to the difficulty of establishing the equilibrium of concentration.

Experimental work on these phenomena is of considerable theoretical importance, since, according to the kinetic theory, they are a direct evidence of a quality of matter out of reach of ordinary thermodynamics: its intrinsic inhomogeneousness. Besides, the determination of the opalescent curves ought to be the most exact method of determining critical temperature and density, and generally of the shape of the equation of state in the neighbourhood of the critical point.

XIV. The Charges on Thermions produced in Air and Hydrogen at Atmospheric Pressure. By J. C. Poneror, M.A., Fellow in Physics, Princeton University $\dagger$.

T $\mathrm{N}$ view of the work done by $\mathrm{O} . \mathrm{W}$. Richardson and F. C. 1 Brown $\ddagger$ on the ralue of the specific charge and the kinetic energy of positive and negative thermions it was thought advisable to determine the value of the charge itself. It was intended to make some preliminary tests in air at atmospheric pressure, and in some other gases, and then try the effect of reducing the pressure. However, some results were obtained at atmospheric pressure which, while of no special meaning in connexion with the experiments made at low pressures already referred to, have still some little interest in themselves. The method adopted was practically that used by Townsend $\S$ in his work on the ions produced by secondary Röntgen radiation. The essential part of the

* Cf. Smoluchowski, Ann. d. Phys. xxv. p. 219 (1908); Einstein, Ann. d. Phys. xxxiii. p. 1295 (1911).

+ Communicated hy Prof. O. W. Richardson.

† O. W. Richardson and F. C. Brown, Phi]. Mag. Sept. 1908; Phil. May. Nov. 1908, Dec. 1908, Nov, 1909. F. C. Brown, Phil. Mag. Oet. 1909.

§ J. S. Townsend, Roy, Soc. Prec. A. rol. 81, p. 464. 
method is to have the ions moving in a uniform field and then examine the distribution in some particular case. A vertical section of the apparatus used is shown in figure $l$.

Fig. 1.

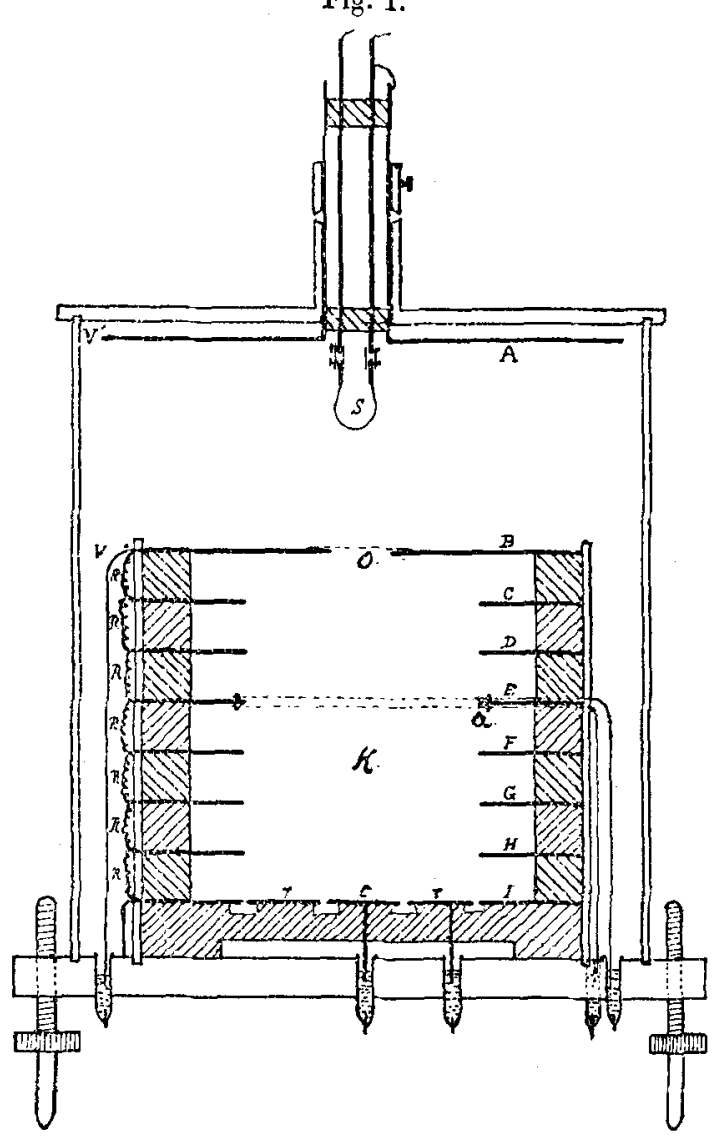

The ions given off by the heated strip $\mathbf{S}$ pass downward under the action of the field and part of them pass through the opening in plate B, which was covered by a grating of fine wire. The stream of ions then opens out so that part fall on the central disk $c$ and the remainder on the ring $r$, and the ratio of these two quantities $Q_{c} / Q_{r}$ was measured by connecting first one and then both disk and ring to an electrometer, when the ratio $Q_{r} / Q_{c}$ is given by

$$
Q_{c} / Q_{r} \text { or } Q_{r}^{\prime} / Q_{:}=C_{2} V_{2} / C_{1} V_{1}-1 \text {, }
$$

according as the ring $r$ or the disk $c$ is first connected to 
the electrometer. In the above $C_{1}, V_{1}, C_{2}$, and $V_{2}$ are the capacities and potentials of the system first connected to the electrometer and of the whole system respectively.

A uniform field in the chamber $\mathrm{K}$ was maintained in the following way :-A series of flat brass rings $\mathrm{B}, \mathrm{C}, \ldots \ldots$ I were placed $1 \mathrm{~cm}$. apart and connected by equal high resistances. $B$ was raised to a potential $V$ and $I$ was earthed.

A was raised to a potential $V^{\prime}$ higher than $V$ and of the same sign. The ring $r$ and the disk $c$ were cut from the same sheet of brass so as to avoid any chance of contact potential between them and their potential in no case differed much from zero.

A theory for the distribution of the ions has been worked out by Townsend * from Maxwell's equations for the diffusion of one gas into another. An outline of this is given below. In this theory it is assumed that the partial pressure of the ions is not appreciably greater than that of an equal number of molecules, but in Townsend's experiments the distribution was found to fit in with the theory except for negative ions where the pressure was low and the gas very dry, and in the present experiments it was found that no correction need be made in any case.

When a uniform stream is passing through the aperture $O$, the partial pressure $(p)$ of the ions at any point in the field of uniform force $\mathrm{Z}$ is given by the equation,

$$
\nabla^{2} p=\frac{\mathrm{N} e \mathrm{Z}}{\Pi} \frac{d p}{d z}
$$

where $\mathrm{N}$ is the number of molecules per cubic centimetre in a gas at atmospheric pressure II and a temperature equal to that of the gas in the experiments.

The solution of this equation is given by $p=f(\mathrm{~N} . e . \mathrm{Z})$, but where the assumption made above is correct and $n=$ the number of ions per c.c. $p=\Pi n / \mathrm{N}$. Whence $n=\phi(\mathrm{N} . e . \mathrm{Z})$, in which all the constants are functions of the coordinates of the position of the point, i.e. of $r$ and $z$.

In the experiments $z=h$, and therefore

$$
\frac{Q_{c}}{Q_{r}}=\frac{\int_{0}^{a} r n d r}{\int_{a}^{b} r n d r},
$$

where $a$ and $b$ are the radii of the disk and ring respectir ely.

* J. S. Townsend, Roy. Soc. Proc. A. vol. 80, p. 207. 
Hence the method gives a method of determining the value of $\phi(N, e . Z)$.

It was not necessary for the purpose of this investigation to determine the form of this function, for in these experiments the method was to compare :

I. The value of $\mathrm{Q}_{c} / \mathrm{Q}_{r}$ given by ions from various sources, and

II. The value of $Z$ necessary to give $Q_{d} / Q_{r}$ a constant value for these different ions.

Thus Townsend found that for hard X-rays,

$$
\phi(\mathrm{NeZ})=\phi(\mathrm{N} e 2 \mathrm{Z})
$$

for all values of $\mathrm{Z}$, and so concluded that $e$, the charge on a positive ion, is equal to twice $e$, the charge on a negative ion.

In the early stages of the experiment there was considerable difficulty in interpreting the results, as the average $\theta$ charge on the positively charged particles given off by the heated platinum seemed to vary from that given by radium to nearly twice this value, while the value given by the negatively charged particles seemed more constant and approximated to twice that given by the ions produced by the radium particles.

This seemed contrary to what one might naturally expect from a consideration of the fact that Townsend had found that the positive ions produced by Röntgen rays carried double charges under certain conditions but that negative jons from the same source did not.

Then the work of Richardson and Brown * with hot metals gave no indications of any ions from this source with double charges. Their experiments, however, did not determine the charge directly and all their measurements were made at low pressures, and this of course might make some difference.

Still an effort was made to see if there might not be some cause, such as a change in the rate of diffusion, for the variation in the ratio $Q_{r} / Q_{c}$ other than an actual change in the charge.

I. It was thought that a variation of the size and position of the strip, causing unequal heating, might account for some part of the variation. However, on investigation this did not seem to give a solution, for the variations were as great when care was taken to keep these as constant as possible as when they were varied widely, and removing the beated strip to a greater distance did not decrease the rariations.

* Richardson \&. F. C. Brown, loc, cit. 
II. It was suggested that perhaps unsteady air-currents were influencing the readings, but from the result above noted and from the fact that all the heating was from the top and that the only opening into the measuring-chamber $(0$, fig. 1) was small and symmetrically placed, it was concluded that this was hardly a possibility. This conelusion was confirmed by the next step.

III. The fact that the strip gave off considerable heat suggested that perhaps the chamber was being heated up, and that the variation in the apparent value of the charge was due to this change of temperature. Then during the early part of the time a strip was being used, the proportion of the charged particles going to the outer ring became gradually larger, indicating either a decrease in the charge, or an increase in the rate of diffusion, and thus lending colour to the above suggestion. However, the fact that this proportion alwiys came to a fairly constant maximum value, and that there was no such variation when the negative ions were being tested, rather pointed the other way.

To test this the variation in the temperature in the chamber " $\mathrm{K}$ " was measured. The thermometer used consisted of fine platinum wire wound on lard rubber pins, which were screwed into boles drilled as near as possible to the inner edge of the central brass ring, as in fios. 1 and 2, in which the dotted line represents the wire. Fig. 1 gives vertical section; fig. 2 gives horizontal view of brass riug in question.

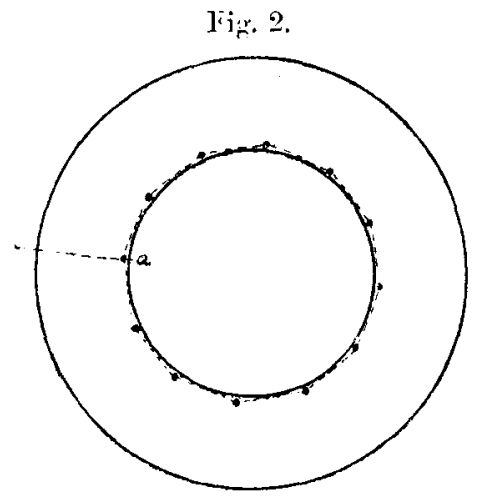

The middie of the wire was soldered to the brass ring at (a) so that it would not disturb the potential gradient appreciably.

The thermometer showed a maximum variation during a Plit. Mag. S. 6. Vol. 23. No. 133. Jun. 1912. N 
set of readings of less than $1^{\circ} \mathrm{C}$.; but when, after the readings for $Q_{r} / Q_{c}$ liad reached a maximum and become steady, the temperature of the whole apparatus was raised about $4^{\circ} \mathrm{C}$., there was no appreciable change in $Q_{r} / Q_{c}$. So the idea that the variation in $Q_{r} / Q_{c}$ might be due to a change of temperature of the air in the chamber " $K$ " was finalfy disposed of. The result seems to confirm the conclusion reached above-that the changes in $\mathrm{Q}_{r} / \mathrm{Q}_{c}$ were not due to unsteady air-currents-- for the outside heat was applied entirely from one side and would be much more likely to cause an uneven distribution of hent, and hence unsteady air-currents, than would the heated strip which was placed centrally above the testing-chamber.

IV. During the early experiments the strips of thin platinum were soldered directly to heavy copper connecting wires, but this was found to be unsatisfactory, as even when care was taken to use as little solder as possible, it fused with the platinum on being heated, and sometimes only three or four readings could be obtained from one strip. Then, doubtless, ionization was obtained from the solder as well as from the platinum. To avoid this the thin platinum was welded to thicker pieces of the same metal and the latter attached to the leads by small screw clips.

It is worth noting that the larger values of $Q_{r} / Q_{c}$ corresponded roughly to the initial positive ionization and to the increased ionization at high temperatures. At first sight it might appear that the increased number of ions might hare something to do with the change in $Q_{r} / Q_{c}$, but if this had any effect it would be due to the mutual repulsions between the ions, and this would be grenter, and hence the spreading of the stream greater, when the ionization was strongest, but the opposite was the case, the number reaching the outer ring being greatest when the ionization was least. Then. too, no such effect was noticed when the ionization from $\mathrm{RaBr}$ was used, though the ionization was much greater than that from the hot platinum. Thus the conclusion that there was an actual change in the charges seemed inevitable, and efforts were made to get at the reason for this variation.

At first, when positive ions were being tested, the platinum was heated to a temperature only sufficiently high to produce these, but not high enough to give negative ions, aud the temperature was increased only when it was desired to obtain the latter. Under these conditions it was found that the positive ions from a fresh strip carried an average charge nearly double that obtained with radium. While the strip 
was being used this average charge at first gradually decreased, but after a few readings hecame fairly constant. If the strip after being heated for a time was left standing at the temperature of the room for a few hours, then on. reheating some of the ions again carried double charges, though the average charge was smaller than with a fresh strip, and the strip came more quickly to a steady state where the average charge was not much higher than the charge on radiun particles. (See Table I.)

TABLE I,

\begin{tabular}{|c|c|c|c|c|}
\hline \multicolumn{2}{|c|}{$\begin{array}{l}\text { Strip at bright } \\
\text { red heat. }\end{array}$} & \multicolumn{2}{|c|}{$\begin{array}{c}\text { Strip at white } \\
\text { heat. }\end{array}$} & \multirow{2}{*}{$\begin{array}{c}\mathrm{RaBr} . \\
100 \mathrm{~V} \\
\text { pos. }\end{array}$} \\
\hline $\begin{array}{r}100 \mathrm{~V} . \\
\text { pos. }\end{array}$ & $\begin{array}{l}100 \mathrm{~V} . \\
\text { pos. }\end{array}$ & $\begin{array}{c}100 \gamma . \\
\text { pos. }\end{array}$ & $\begin{array}{l}60 \mathrm{~V} . \\
\text { pos. }\end{array}$ & \\
\hline $1 \cdot 0$ & Same strip & 10.5 & $1: 85$ & 17 \\
\hline $1-1$ & $\begin{array}{l}\text { ufter rest of } \\
10 \text { hrs }\end{array}$ & 105 & $1 \cdot 7$ & 16 \\
\hline $1 \cdot 1$ & $1 \cdot 3$ & 105 & 165 & 18 \\
\hline 12 & $1: 4$ & $\& \mathrm{c}$. & 17 & neg. \\
\hline $1-2$ & 1.55 & neg. & neg. & 17 \\
\hline 13 & 1.5 & $1 \cdot 1$ & $1 \cdot 7$ & $1: 7$ \\
\hline 13 & 1.50 & $1 \cdot 15$ & $1: 6$ & 16 \\
\hline $1 \cdot 4$ & \& & $1 \cdot 1$ & $1 \cdot 9$ & $1 \cdot 8$ \\
\hline $1-5$ & & $1: 0$ & $1: 8$ & 1.8 \\
\hline $1-56$ & & 100 & \&e. & \\
\hline $1 \cdot 55$ & & $1 \cdot 15$ & ạverage & \\
\hline 1.5 & & $\cdot 97$ & charge & \\
\hline 1.5 & & $1 \cdot 15$ & $1 \cdot \pi$ & \\
\hline $1 \cdot 6$ & & \&e. & & \\
\hline \&c. & & & & \\
\hline
\end{tabular}

In the table above is given the value of $Q_{r} / Q_{c}$ from several strips under the conditions indicated. The first three sets of readings from two strips at 100 rolts are shown graphically 
in fig. 3. The charge is, of course, inversely proportional to the potential difference necessary to give the same value of $Q_{r} / Q_{c}$.

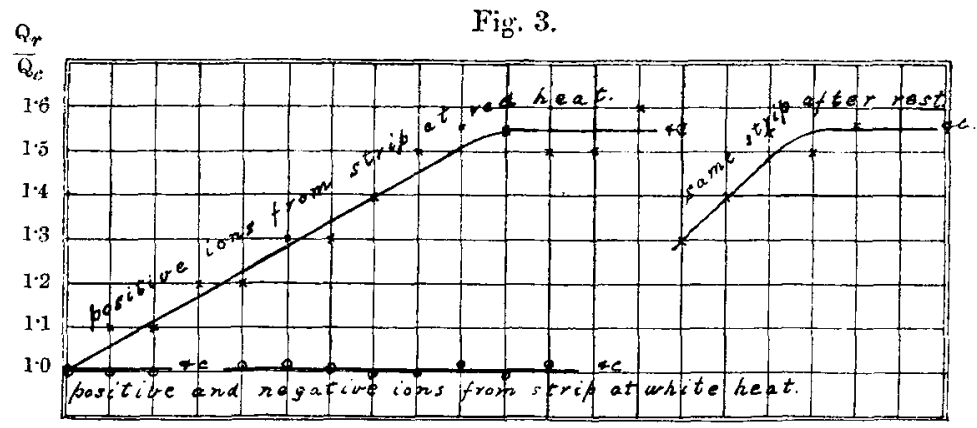

Thus it would seem that at a temperature only sufficiently high to give positive ionization, some of the ions from a fresh strip, or from one which had been resting in air, carry charges which are double the atomic charge; but when the strip is heated for a time a gradual change takes place, and as the large initial positive leak dies away a smaller and smaller proportion carry double charges, until a steady state is reached where the average charge is nearly equal to the atomic charge.

However, as noted above, no such change takes place with the negative ions, some of which at all times carry double charges. Then, too, when the positive ionization from a strip, heated to a sufficiently high temperature to give negative ions, was tested it was found that the average charge was about the same as for the negative ions. This result suggested that probably the negative ions also would carry single charges only, if obtained from a strip at a sufficiently low temperature. The apparatus as arranged did not admit of very low pressures being obtained, so hydrogen at atmospheric pressure was used and the strip heated in this.

As expected, the negative as well as positive ions carried single charges only when obtained from a strip at the lower temperature, and when this temperature was raised, both positive and negative ions carried some double charges. The proportion of these double charges to the whole number of ions rose gradually with the temperature of the strip just as with positive ions in air.

No attempt was made to measure the temperature of the strip, but keeping the same strip the heating cur:ent was varied from the smallest which would give positive ionization 
to the greatest that it was thought that the strip would stand, and in taking the readings the current was gradually increased, and then lessened again to eliminate errors which might creep in from changes in the wire due to heating.

In the table below are given the differences of potential between the plates B and I which were found necessary to give the same value of $Q_{r} / Q_{j}$ as 200 volts gave with the ionization from radium. The average results obtained from single strips are given, as combined results from different strips would have no meaning, because the same current with a different strip might mean quite a different temperature.

The numbers given for potential differences are of course inversely proportional to the average charge carried by the ions in question.

TABLE II.

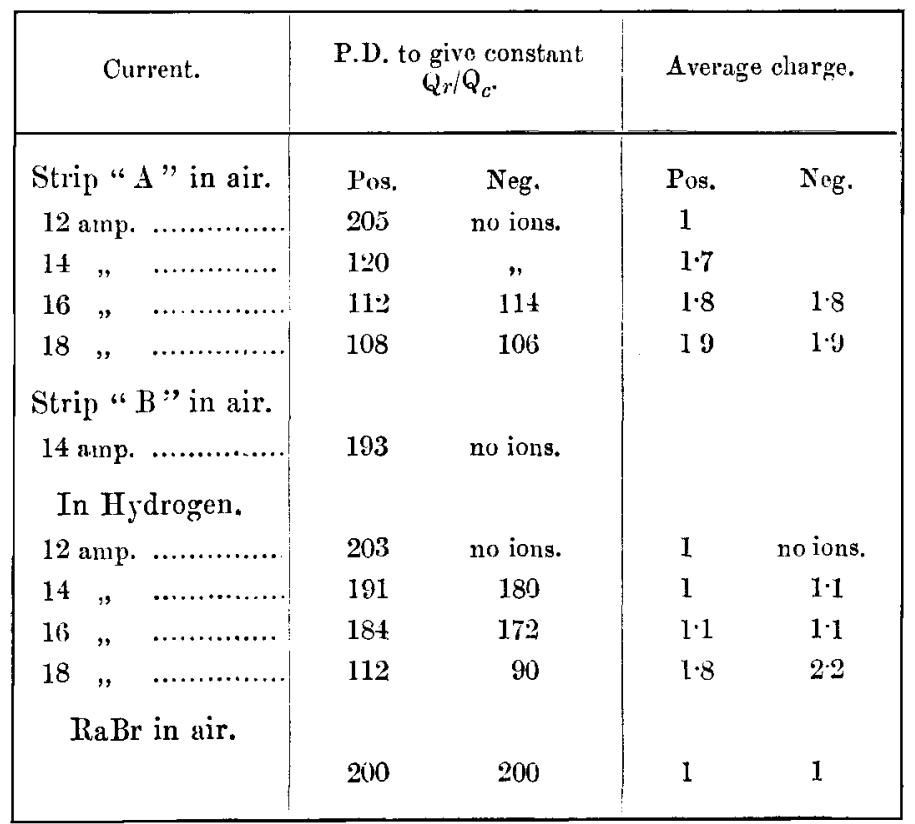

It is probable also, although this was not tested, that at low pressures in air the same variations might be found.

A little work was done with positive ions from nichrome, which indicated that practically the same results might be looked for, but the experiments were not satislactory. It was found impossible with the apparatus at hand to roll the 
nichrome thin enough, and larger currents were necessary than could be carried for any great length of time by some of the leads in use: Then, too, it was found difficult to weld the nichrome and it was soldered to copper leads directly, with the same results as in the case of platinum, the solder fused with the nichrome so that but few few readings could be obtained from one strip, and it was uncertain whether the fonization was due entirely to the nichrome or partly to the heated solder:

In the early stages of the experiment some doubt was felt as to whether these double charges might not be due to two ions; each with a single charge and each carrying along a load of alr particles sticking together after being given off from the hot metal, and Millikan's * recent work did seem to make this worth considering. However, the fact that the number of these double charges depends entirely on the temperature of the strip and not at all on the temperature of the gas in the testing-chamber makes it seem highly improbable.

With the idea of confirming, or otherwise, these results some experiments on the velocity of ions from the same source were undertaken but are not yet ready for publication. This much, however, may be said. The maximum velocity was found not to vary with the temperature of the wire, but Rutherford $\dagger$ found that the average and minimum velocities decreased with incrense in the temperature of the wire. This is in accord with the theory worked out by Wellisch $\ddagger$ if we assume that at high temperatures some of the ions carry charges $2 e$ rather than $e$, for his theory would lead to the conclusion that a particle carrying a charge $e$ would have a greater mobility than one carrying a charge $2 e$.

In conclusion I want to express my thanks to Prof. $\mathrm{O}$. W. Richardson for suggesting the experiment, and for the advice given me from time to time during its progress.

I wish also to thank Mr. C. Bol for advice and help with the mechanical details.

* R. A. Millikan and H. Fletcher, Phil. Mag. June 1011, p. 753.

$\uparrow$ E. Rutherford, Phys. Rev. xiii. p. 321 (1901).

$\ddagger$ F. M. Wellisch, Phil: Trans. A, rol. ccix: p. 249. 